\title{
The Liberation of Fractalkine in the Dorsal Horn Requires Microglial Cathepsin S
}

\author{
Anna K. Clark, Ping K. Yip, and Marzia Malcangio \\ Wolfson Centre for Age Related Diseases, King's College London, Guy's Campus, London SE1 1UL, United Kingdom
}

\begin{abstract}
Understanding of the sequence and nature of the events that govern neuron-microglia communication is critical for the discovery of new mechanisms and targets for chronic pain treatment. The neuronal chemokine fractalkine (FKN) and its microglial receptor CX3CR1 may mediate such a function in the dorsal horn of the spinal cord after cleavage of the extracellular domain of this transmembrane chemokine by a protease. Here we report that in neuropathic rat dorsal horn, with dorsal root-attached preparations, soluble FKN (sFKN) contents are increased in the superfusates collected after noxious-like electrical stimulation of ipsilateral primary afferent fibers. The increase of sFKN is prevented by morpholinurea-leucine-homophenylalanine-vinyl sulfone-phenyl (LHVS), an irreversible inhibitor of cathepsin S (CatS) whose proteolytic activity is also increased in the superfusates. The source of CatS activity is microglial cells activated by the peripheral nerve injury and secreting the enzyme, as a result of primary afferent fiber stimulation. Indeed, the acute activation of dorsal horn microglia by lipopolysaccharide results in increased CatS activity in the superfusates, followed by increased sFKN contents. Consistent with these observations ex vivo, the levels of both sFKN and CatS activity in CSF samples increased significantly after peripheral nerve injury, associated with spinal microglial activation. Finally, because we found that both FKN immunoreactivity and mRNA are confined to dorsal horn neurons, we suggest that under neuropathic conditions, noxious stimulation of primary afferent fibers induces release of CatS from microglia, which liberates FKN from dorsal horn neurons, thereby contributing to the amplification and maintenance of chronic pain.
\end{abstract}

\section{Introduction}

The activation of microglia which follows a peripheral insult can be considered as an adaptation to tissue stress and malfunction (Medzhitov, 2008) that contributes to the development and subsequent maintenance of chronic pain (Romero-Sandoval et al., 2008; Milligan and Watkins, 2009). Spinal microglia respond quickly to injury, upregulating cell surface proteins and increasing their synthesis and release of inflammatory mediators, including cytokines and proteases that can sensitize neurons, thereby establishing a positive feedback which contributes to nociceptive signaling (Abbadie et al., 2009). Accordingly, the inhibition of microglial targets can reduce hypersensitivity in neuropathic pain states. In particular, the microglial protease cathepsin $\mathrm{S}$ (CatS) is upregulated in microglial cells after nerve injury, and CatS inhibitors reverse neuropathic pain behaviors (Clark et al., 2007).

It is now essential to establish the sequence and nature of the events that govern neuron-microglia communication in the dorsal horn in an effort to discover new mechanisms and targets for chronic pain. In this context, the chemokine fractalkine (FKN) and its receptor CX3CR1 are uniquely qualified to function as neuron-microglia signals for several reasons (Milligan et al.,

Received Feb. 18, 2009; revised March 24, 2009; accepted April 28, 2009

This work is funded by the Wellcome Trust. P.K.Y. is supported by the Medical Research Council. We thank Dr. Amelia A. Staniland for technical assistance.

Correspondence should be addressed to Dr. Anna K. Clark, Wolfson Centre for Age Related Diseases, Kings College London, Wolfson Wing, Hodgkin Building, Guy's Campus, London SE1 1UL, UK. E-mail: anna.clark@kcl.ac.uk. DOl:10.1523/JNEUROSCI.0828-09.2009

Copyright $\odot 2009$ Society for Neuroscience $\quad$ 0270-6474/09/296945-10\$15.00/0
2008). First, FKN is constitutively expressed by spinal cord neurons and the cell bodies of sensory neurons in the dorsal root ganglia (DRGs) (Verge et al., 2004; Lindia et al., 2005; Clark et al., 2007), whereas CX3CR1 is expressed by spinal microglia (Verge et al., 2004; Lindia et al., 2005). Second, after peripheral nerve injury, whereas FKN immunoreactivity remains unaltered in the dorsal horn, CX3CR1 is extensively upregulated (Verge et al., 2004; Lindia et al., 2005). Third, the intrathecal administration of the chemokine domain of FKN results in thermal (Milligan et al., 2004, 2005) and mechanical (Milligan et al., 2004, 2005; Clark et al., 2007) hypersensitivity that is prevented by pretreatment with neutralizing agents against CX3CR1 (Milligan et al., 2004, 2005) or FKN itself (Clark et al., 2007), and is absent in CX3CR1 knockout mice (Clark et al., 2007). FKN induces nociceptive behaviors after activation of the CX3CR1 receptor on microglia, activation of p38 mitogen-activated protein kinase (MAPK)-mediated pathways (Clark et al., 2007; Zhuang et al., 2007) and release of interleukin (IL)-1 $\beta$, IL-6, and nitric oxide (Milligan et al., 2005). Finally, impairment of FKN/CX3CR1 signaling after nerve injury attenuates neuropathic pain behaviors (Milligan et al., 2004; Clark et al., 2007).

At present, FKN is the only member of the CX3C class of chemokines, existing as both an extracellular membrane-bound form and a soluble form (Bazan et al., 1997; Pan et al., 1997). To activate the CX3CR1 receptor on microglia, the soluble form is cleaved from neuronal membranes by the protease CatS, which is expressed and released by activated microglia (Clark et al., 2007).

Here we have established the modalities for soluble FKN $(\mathrm{sFKN})$ liberation in the spinal cord and their dependence on 
microglial activation and release of CatS proteolytic activity. We demonstrate that neuronal FKN cleavage occurs in the dorsal horn under highly regulated conditions associated with increased nociception.

\section{Materials and Methods}

All experiments were performed using male Wistar rats in accordance with United Kingdom Home Office regulations.

\section{Surgical procedures}

A well established rodent model of neuropathy was used to induce neuropathic pain. Adult male rats $(200-220 \mathrm{~g})$ received a partial ligation (PNL) of the left sciatic nerve (Seltzer et al., 1990). Briefly, under isoflurane/ $\mathrm{O}_{2}$ inhalation anesthesia a small incision was made midway up the left thigh to expose the sciatic nerve. The nerve was carefully cleared of surrounding connective tissues at a site near the trochanter just distal to the point at which the posterior biceps semitendinosus nerve branches off the common sciatic nerve. A 7-0 silk suture was inserted into the nerve with a $3 / 8$ curved, reversed-cutting micropoint needle, and tightly ligated so that $1 / 3$ to $1 / 2$ of the nerve thickness was held within the ligature. In sham animals the sciatic nerve was exposed but not ligated. In a separate group of rats a unilateral rhizotomy was performed at spinal lumbar level L5. Briefly, a hemilaminectomy was performed to expose the left L5 dorsal root, which was then crushed between the closed blades of a watchmaker's forceps for $10 \mathrm{~s}$.

\section{CSF and tissue collection}

CSF samples were collected from adult male rats $7 \mathrm{~d}$ after either PNL or sham surgery to quantify levels of FKN. Under anesthesia, the skin covering the occipital bone and the cervical dorsum was incised, and the occipital bone and upper cervical vertebral arc were exposed. The atlanto-occipital membrane was identified and carefully cleared of surrounding tissues. The needle of a 29 gauge insulin syringe (BD Biosciences) was inserted horizontally through the lateral atlanto-occipital membrane, and $50 \mu \mathrm{l}$ of CSF was withdrawn and immediately flashfrozen in liquid nitrogen for quantification of FKN content or CatS activity. A laminectomy was then performed to expose the lumbosacral spinal cord. The L4-L6 spinal cord was then excised, divided into left and right halves, and separately flash-frozen in liquid nitrogen for quantification of tissue FKN levels by ELISA.

\section{Release of FKN, interleukin-1 $\beta$, and calcitonin gene-related peptide from dorsal horn slices}

Horizontal dorsal horn slices ( $400 \mu \mathrm{m}$ thick) with dorsal roots attached were obtained from the lumbar spinal cord of adult rats as previously described (Clark et al., 2006). Briefly, lumbosacral spinal cord was excised and longitudinally hemisected, producing a horizontal slice with L4 and L5 dorsal roots attached. One slice was obtained from each rat, mounted in the central compartment of a three-compartment chamber, and continuously superfused $(1 \mathrm{ml} / \mathrm{min})$ with oxygenated $\left(95 \% \mathrm{O}_{2}+\right.$ $5 \% \mathrm{CO}_{2}$ ) Krebs' solution (in $\mathrm{M}$ : $118 \mathrm{NaCl}, 4 \mathrm{KCl}, 1.2 \mathrm{MgSO}_{4}, 1.2$ $\mathrm{KH}_{2} \mathrm{PO}_{4}, 25 \mathrm{NaHCO}_{3}, 2.5 \mathrm{CaCl}_{2}$, and 11 glucose) containing $0.1 \%$ BSA and $20 \mu \mathrm{g} / \mathrm{ml}$ bacitracin to minimize protein degradation. The dorsal roots were placed in the lateral compartments and immersed in mineral oil to avoid dehydration. Before, during, and after dorsal root/chemical stimulation, fractions of 3 or $8 \mathrm{ml}$ of the superfusates were collected from the central compartment in ice-chilled glass tubes to minimize FKN/ IL- $1 \beta$ loss, or in acetic acid ( $0.1 \mathrm{~m}$ final concentration; VWR) to stabilize calcitonin gene-related peptide (CGRP).

Experiment 1: electrically evoked release of FKN and CGRP from the naive dorsal horn. Burst electrical stimulation (ES) was applied to the L4 and L5 dorsal roots of naive spinal cord slices as previously described (Lever et al., 2001). ES consisted of 75 trains of four pulses at $100 \mathrm{~Hz}$ separated by $0.2 \mathrm{~s}$ intervals. Square pulses of $0.5 \mathrm{~ms}$ duration and $20 \mathrm{~V}$ were used to recruit both $\mathrm{A}$ and $\mathrm{C}$ fibers. Eight $3 \mathrm{ml}$ fractions were collected before stimulation ( $0-24 \mathrm{~min})$ to measure basal levels of FKN or CGRP. These values were then pooled and expressed as "Basal." One fraction was collected during ES (24-27 min), and three fractions after
ES to assess recovery to basal levels of FKN (R1, 27-30 min; R2, 30-33 min; R3, 33-36 min).

Experiment 2: capsaicin-evoked release of FKN and CGRP from the naive dorsal horn. Capsaicin was solubilized in ethanol (1 mM) and then diluted in Krebs' solution and superfused ( $1 \mu \mathrm{M}$ for $3 \mathrm{~min}$; Sigma) through naive spinal cord slices as previously described (Lever et al., 2001). Eight $3 \mathrm{ml}$ fractions were collected before superfusion ( $0-24 \mathrm{~min})$ to measure basal levels of FKN or CGRP, followed by one fraction during capsaicin superfusion (24-27 $\mathrm{min}$ ), and three fractions after capsaicin to assess recovery to basal levels of FKN (R1, 27-30 min; R2, 30-33 min; R3, 33-36 min).

Experiment 3: electrically evoked release of FKN in nerve-injured and sham dorsal horn. Dorsal horn slices were obtained from nerve-injured and sham rats $7 \mathrm{~d}$ after surgery. Behavioral testing was performed on day 5 postsurgery to confirm the development of mechanical hypersensitivity (see below for behavioral testing methods). ES was applied to the ipsilateral L4 and L5 dorsal roots. Eight $3 \mathrm{ml}$ fractions were collected before stimulation $(0-24 \mathrm{~min})$ to measure basal levels of FKN. One fraction was collected during ES (24-27 $\mathrm{min})$ and two fractions after ES to assess recovery to basal levels of FKN (R1, 27-30 min; R2, 30-33 min).

Experiment 4: pharmacological modulation of electrically evoked FKN release in nerve-injured dorsal horn. Dorsal horn slices were obtained from nerve-injured rats $7 \mathrm{~d}$ after surgery. ES was applied to the ipsilateral L4 and L5 dorsal roots of nerve-injured dorsal horn slices. Pharmacological manipulation of FKN release was achieved by superfusion of the irreversible CatS inhibitor LHVS (morpholinurea-leucinehomophenylalanine-vinyl sulfone-phenyl) ( $1 \mu \mathrm{M}$; NeoMPS Inc) in one fraction before and during ES (6 min in total).

Experiment 5: lipopolysaccharide-induced release of FKN and IL-1 $\beta$ in naive dorsal horn. Lipopolysaccharide (LPS) (Escherichia coli; Sigma) was solubilized in $\mathrm{H}_{2} \mathrm{O}(10 \mathrm{mg} / \mathrm{ml})$ and then diluted in Krebs' solution and superfused $(10 \mu \mathrm{g} / \mathrm{ml}$ for $8 \mathrm{~min})$ through naive spinal cord slices as previously described (Clark et al., 2006). Three $8 \mathrm{ml}$ fractions were collected before stimulation $(0-24 \mathrm{~min})$ to measure basal levels of FKN or IL-1 $\beta$. One fraction was collected during LPS superfusion ( $24-32 \mathrm{~min}$ ), and three to four fractions after LPS to assess recovery to basal levels of IL- $1 \beta$ and FKN, respectively (R1, 32-40 min; R2, 40-48 min; R3, 48-56 min; R4, 56-64 min).

Experiment 6: pharmacological modulation of LPS-induced release of FKN and IL- $1 \beta$ in naive dorsal horn. LPS was superfused $(10 \mu \mathrm{g} / \mathrm{ml}$ for 8 $\mathrm{min}$ ) through naive spinal cord slices. Pharmacological manipulation of FKN/IL- $1 \beta$ release was achieved by superfusion of the irreversible CatS inhibitor LHVS ( $1 \mu \mathrm{M}$; NeoMPS Inc) in one fraction before and during LPS superfusion (16 $\mathrm{min}$ in total).

\section{Processing of collected superfusate samples}

To quantify FKN and IL- $1 \beta$ content in superfusates, 3 or $8 \mathrm{ml}$ samples were desalted and concentrated by Ultrafree- $153 \mathrm{~K}$ and $10 \mathrm{~K}$ centrifugal devices (Millipore), respectively. Retentates were lyophilized, reconstituted in appropriate sample buffer, and assayed for either FKN or IL-1 $\beta$ content by ELISA.

To quantify CGRP content, separate samples were partially purified and desalted using Sep-Pak $\mathrm{C}_{18}$ reverse-phase silica gel cartridges (Waters Associates). Cartridges were conditioned with acetonitrile (VWR) and trifluoroacetic acid (TFA) $(0.1 \%$, VWR). The peptide was then eluted from columns using acetonitrile/TFA (80:20) solution. Eluates were then dried by evaporation under nitrogen and reconstituted in 300 $\mu \mathrm{l}$ of sample buffer (SPI bio) and assayed for CGRP content by ELISA.

\section{FKN, IL-1 $\beta$, and CGRP ELISA}

Ninety-six-well colorimetric "Sandwich" ELISA plates (RayBio Rat Fractalkine ELISA Kit, Tebu-Bio) were used to determine FKN content. Rat recombinant FKN standards $(100 \mu \mathrm{l}$ of $2000-0 \mathrm{pg} / \mathrm{ml})$ and $100 \mu \mathrm{l}$ of unknown samples were run in duplicate following the manufacturer's instructions. The optical density of each well was determined at a wavelength of $450 \mathrm{~nm}$. Samples were considered FKN positive when the signal was higher than background signal (modified Krebs' solution) and within the range of the standard curve. Data are expressed as percentage of FKN content in the basal fractions.

Rat recombinant FKN (R\&D Systems) was used to assess FKN recov- 
ery. This was determined by adding known concentrations (0-2000 pg/ $\mathrm{ml}$ ) of recombinant protein to modified Krebs' solution that had not been superfused through dorsal horn tissue, followed by processing under the same conditions as experimental samples. Recovery was $>80 \%$ at all concentrations assayed.

Similarly, samples were assayed for IL- $1 \beta$ (IL-1 $\beta /$ IL-1F2 Quantikine ELISA Kit; R\&D Systems) or CGRP (rat CGRP enzyme immunoassay kit; SPI bio) content. Rat recombinant IL- $1 \beta$ (50 $\mu \mathrm{l}$ of $2000-0 \mathrm{pg} / \mathrm{ml})$ or CGRP standards $(100 \mu \mathrm{l}$ of $0-500 \mathrm{pg} / \mathrm{ml})$ and unknown samples were run in duplicate following the manufacturer's instructions. The optical density of each well was determined at a wavelength of $450 \mathrm{~nm}$. Data are expressed as percentage of IL- $1 \beta$ or CGRP content in basal fractions.

\section{Cathepsin S activity assay}

CatS activity was assessed by incubating samples with the methylcoumarylamide substrate benzyloxycarbonyl-L-valyl-L-valyl-arginine 4-methyl-coumaryl-7-amide (50 $\mu \mathrm{M}$; Peptide Institute) and measuring the fluorescence intensity resulting from liberation of 7-amino-4methylcoumarin (Kirschke and Wiederanders, 1994). Dorsal horn superfusate samples and CSF samples were incubated with dithiothreitol (5 mM; Sigma) at $37^{\circ} \mathrm{C}$ for $10 \mathrm{~min}$ to activate CatS. The methylcoumarylamide substrate ( $50 \mu \mathrm{M}$ in $0.01 \mathrm{M}$ potassium phosphate buffer and $5 \mathrm{~mm}$ disodium EDTA, pH 7.5) was then added to the samples and the increase in fluorescence was measured using a spectrophotometer (excitation 360 $\mathrm{nm}$; emission $460 \mathrm{~nm}$ ) (FlexStation and SOFTmax Pro software, Molecular Devices) after $10 \mathrm{~min}$ incubation at $37^{\circ} \mathrm{C}$.

\section{Immunohistochemistry}

After behavioral experiments, rats were, under pentobarbital anesthesia, transcardially perfused with $0.9 \%$ saline solution followed by $4 \%$ paraformaldehyde in $0.1 \mathrm{~m}$ phosphate buffer. The lumbar spinal cord was excised and postfixed for $4 \mathrm{~h}$ in the perfusion fixative. At the completion of the release experiments ( $\sim 35-40 \mathrm{~min}$ after ES or 65-70 min after LPS superfusion), dorsal horn slices were fixed in $4 \%$ paraformaldehyde (overnight at $4^{\circ} \mathrm{C}$ ). All tissues were then cryoprotected in $20 \%$ sucrose in $0.1 \mathrm{M}$ phosphate buffer $\left(72 \mathrm{~h}\right.$ at $\left.4^{\circ} \mathrm{C}\right)$ and frozen in O.C.T. embedding compound (VWR). Transverse sections $(20 \mu \mathrm{m})$ were cryostat cut and thaw-mounted onto glass slides. Slides were incubated overnight with primary antibody solution for FKN (goat anti-fractalkine, 1:100; R\&D Systems), CGRP (rabbit anti-calcitonin gene-related peptide, 1:2000; Sigma), IB4 (isolectin B4) (tetramethylrhodamine isothiocyanate conjugated, 1:200; Sigma), NF200 (mouse anti-neurofilament 200) (CBL212, 1:400; Millipore Bioscience Research Reagents), NeuN (mouse antineuronal nuclei) (MAB377, 1:500; Millipore Bioscience Research Reagents), Iba-1 (rabbit anti-ionized calcium-binding adapter molecule-1) (1:1000; Wako Chemicals), or phosphorylated p38 MAPK (rabbit antip-p38 MAPK, p-p38; 1:100; Cell Signaling Technology). For examination of CatS-expressing microglia, sections were processed for "antigen retrieval" by microwaving in Antigen Unmasking solution (1:100; Vector Laboratories) as previously described (Barclay et al., 2007; Clark et al., 2007). Sections were then incubated with primary antibody for CatS (goat anti-cathepsin S M-19; 1:100; Santa Cruz Biotechnology). Slides were then incubated with secondary antibody solutions (IgG-conjugated Alexa Fluor 488; Invitrogen). FKN expression was visualized with extra avidin-FITC (1:500; Sigma) after signal amplification with avidin-biotin peroxidase complex (Vectastain ABC Elite Kit, Vector Laboratories) and biotinyl tyramide (PerkinElmer Life Sciences). Slides were coverslipped with Vectashield mounting medium (Vector Laboratories) and visualized under a Zeiss Axioplan 2 fluorescent microscope (with ApoTome).

Fluorescence in situ hybridization and immunohistochemistry DNA probes and labeling. FKN oligonucleotide sequence (5'GCACCAGGACGTACGAGTTACTGCCACAGCTAC-3') was designed from rat FKN cDNA (GenBank accession no. BC070938). The oligonucleotide was then labeled with biotin-11-dUTP using the biotin $3^{\prime}$ end DNA labeling kit (\#89818; Pierce Biotechnology) according to the manufacturer's instructions.

Fluorescence in situ hybridization procedure. Fluorescence in situ hybridization (FISH) was performed similarly to previously published methods (Rattray and Michael, 1998; Zaidi et al., 2000; Wong et al.,
2006). Under pentobarbital anesthesia, animals were transcardially perfused with diethylpyrocarbonate (DEPC)-treated heparinized saline followed by $4 \%$ paraformaldehyde. The lumbar spinal cord was excised and postfixed for $2 \mathrm{~h}$ in the perfusion fixative. Tissues were then cryoprotected in $20 \%$ sucrose in $0.1 \mathrm{M}$ phosphate buffer $\left(72 \mathrm{~h}\right.$ at $\left.4^{\circ} \mathrm{C}\right)$ and frozen in O.C.T. embedding compound (VWR). Transverse sections $(12 \mu \mathrm{m})$ were cryostat cut and thaw-mounted onto Superfrost Plus glass slides (VWR). Sections were washed in DEPC-treated $10 \mathrm{~mm}$ PBS and then dehydrated through graded concentrations of alcohol and air dried. Slides were incubated overnight at $50^{\circ} \mathrm{C}$ with $100 \mu \mathrm{l}$ of biotin-labeled FKN oligonucleotide probe $(2 \mathrm{nM})$ in hybridization buffer. Posthybridization washes were: twice in $1 \times$ standard saline citrate (SSC) $(15$ min, room temperature), twice in $1 \times \operatorname{SSC}\left(15 \mathrm{~min}, 50^{\circ} \mathrm{C}\right)$, then twice in $1 \times$ SSC ( $15 \mathrm{~min}$, room temperature). Sections were then washed in PBS for $5 \mathrm{~min}$ and incubated with $0.3 \%$ hydrogen peroxide for $10 \mathrm{~min}$. FKN mRNA was then visualized using extra avidin-FITC (1:400; Sigma) after signal amplification with the Vectastain ABC Elite Kit (Vector Laboratories) and biotinyl tyramide (PerkinElmer Life Sciences).

Immunohistochemistry. Post-in situ hybridization sections were incubated overnight with primary antibody for NeuN (mouse anti-neuronal nuclei; MAB377, 1:150; Millipore Bioscience Research Reagents), followed by secondary antibody solution (IgG-conjugated Alexa Fluor 546; Invitrogen), then coverslipped with Vectashield mounting medium (Vector Laboratories) and visualized under a Zeiss Axioplan 2 fluorescence microscope (with ApoTome).

FISH control. To determine whether the FKN oligonucleotide probes bound specifically to FKN mRNA, RNase control slides were incubated at $37^{\circ} \mathrm{C}$ in $20 \mathrm{mg} / \mathrm{ml}$ RNase A for $30 \mathrm{~min}$, then for $30 \mathrm{~min}$ in RNase buffer $(0.5 \mathrm{~m} \mathrm{NaCl}, 1 \mathrm{~mm}$ EDTA, $10 \mathrm{~mm}$ Tris, $\mathrm{pH}$ 8.0) before being air dried. Hybridization steps were then performed as described above.

\section{Intrathecal LPS-induced mechanical hyperalgesia and}

\section{behavioral testing}

Under $20 \%$ isoflurane/ $\mathrm{O}_{2}$ anesthesia, LPS was intrathecally injected twice into the rat lumbar region (between the L5 and L6 vertebrae) of the spine using a $26 \mathrm{G} \mathrm{3/8}$ inch needle as previously described (Cahill et al., 2003; Clark et al., 2006). Briefly, rats received a $2 \mu \mathrm{g}$ intrathecal dose of LPS (dissolved in $10 \mu \mathrm{l}$ of $0.9 \%$ saline) to prime the immune system. Twenty-four hours later, rats received a second intrathecal injection of one of the following: $2 \mu \mathrm{g} / 10 \mu \mathrm{l}$ LPS, vehicle ( $10 \mu \mathrm{l}, 0.9 \%$ saline), LHVS alone (10 $\mu \mathrm{l}$ of $50 \mathrm{nmol}$; NeoMPS Inc), or $2 \mu \mathrm{g} / 10 \mu \mathrm{l}$ LPS plus LHVS. No LPS-induced piloerection, shivering, or hunched posture was observed.

Mechanical sensitivity was assessed by measuring paw withdrawal threshold (PWT) to increasing mechanical force applied to the dorsal surface of the rat paw using an Analgesymeter (Ugo-Basile). Mechanical hyperalgesia was defined as reduced threshold of hind paws compared with naive baseline thresholds. PWT readings were taken before LPS injection and then at set intervals after injection. In addition, PWT readings were assessed before and at day 5 post-PNL or sham surgery in animals used for release experiments.

\section{Quantification and statistics}

Quantitative assessment of Iba-1, p-p38, and CatS immunoreactivity (ir) was determined by counting the number of profiles within a fixed area of the dorsal horn of the spinal cord. A box measuring $10^{4} \mu \mathrm{m}^{2}$ was placed onto areas of the lateral, central, and medial dorsal horn, and the number of profiles positive for each marker was counted within this area. Similarly, quantitative assessment of CatS-ir and FKN-ir was performed by determining the immunofluorescence intensity. The background fluorescence intensity of each tissue section was also determined and subtracted from values obtained. Intensity values were then expressed as a ratio of ipsilateral to contralateral dorsal horn (ipsi/contra). This measurement protocol was performed on three L5 spinal sections from each animal. All samples were scored blind until analysis was complete.

Statistical analysis for all experiments was performed on raw data. For release and immunohistochemical studies, one-way repeated-measures ANOVA followed by Tukey's post hoc test was used. For the analysis of behavioral data, two-way repeated-measures ANOVA followed by Tukey's post hoc test was used. $p<0.05$ was set as the level of statistical significance. 

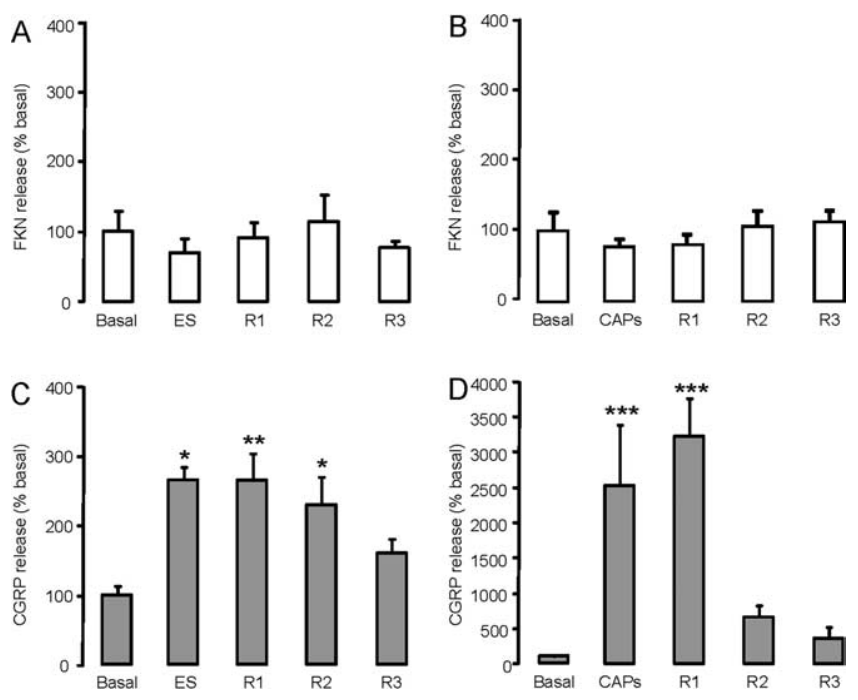

Figure 1. $E S$ of $L 4$ and $L 5$ dorsal roots does not evoke release of FKN from the naive dorsal horn. $A$, In naive dorsal horn, ES of dorsal roots ( 75 trains of four pulses separated by $0.2 \mathrm{~ms}, 100$ $\mathrm{Hz} ; 20 \mathrm{~V}$ intensity, $0.5 \mathrm{~ms}$ duration) does not increase FKN levels over dorsal horn superfusate basal contents of $0.5 \pm 0.1 \mathrm{pg} / 3 \mathrm{ml}$ fraction $(n=6) . \mathrm{R} 1, \mathrm{R} 2$, and $\mathrm{R} 3$ indicate $3 \mathrm{ml}$ recovery fractions. $B$, Capsaicin (1 $\mu \mathrm{m}$ for $3 \mathrm{~min}$ ) does not evoke release of FKN from naive dorsal horn slices over basal levels of $0.8 \pm 0.2 \mathrm{pg} / 3 \mathrm{ml}$ fraction $(n=7)$. C, ES of $L 4$ and $L 5$ dorsal roots evokes significant release of CGRP from naive spinal cord slices $(n=6)$. Basal release $=8.2 \pm$ $1.0 \mathrm{pg} / 8 \mathrm{ml}$ fraction. $D$, Capsaicin evokes significant release of CGRP from the naive dorsal horn $(n=7)$. Basal release $=8.6 \pm 2.4 \mathrm{pg} / 8 \mathrm{ml}$ fraction. ${ }^{*} p<0.05,{ }^{* *} p<0.01,{ }^{* * *} p<0.001$, one-way ANOVA, post hoc Tukey's test.

\section{Results}

Liberation of soluble FKN in the dorsal horn after primary afferent fiber activation

We have used the dorsal horn with dorsal roots attached preparation obtained from naive, peripheral nerve-injured, and sham rats to investigate whether FKN is liberated under conditions that mimic the transmission of noxious stimulation from primary afferent terminals to dorsal horn neurons. In naive dorsal horns, neither electrical stimulation of the dorsal roots at high intensity, which recruits high-threshold nociceptive fibers, nor chemical activation of nociceptive fiber terminals by capsaicin induced changes in the collected superfusates of FKN contents (Fig. $1 A, B)$. In contrast, both electrical stimulation and superfusion of capsaicin evoked significant release of CGRP (Fig. 1C,D). These data suggest that FKN is not released in the dorsal horn after intense noxious-like stimulation of primary afferent fibers, which is normally associated with release of nociceptive transmitters (Lever et al., 2001), such as CGRP.

In contrast, in nerve-injured but not sham dorsal horn slices, electrical stimulation of the dorsal roots at nociceptive fiber strength evoked a significant increase of sFKN in dorsal horn superfusates which recovered to basal values after stimulation (Fig. 2A), indicating that a previous injury to primary afferent fibers created the conditions for $\mathrm{sFKN}$ liberation.

We have recently suggested that after peripheral nerve injury, activated microglia in the dorsal horn release the protease CatS, which is pronociceptive via the liberation of FKN (Clark et al., 2007). Therefore, we first evaluated the effect of the CatS inhibitor LHVS (Clark et al., 2007; Lützner and Kalbacher, 2008) on the electrically evoked increase of sFKN in the dorsal horn superfusates of nerve-injured rats and found that the presence of LHVS prevented the increase in sFKN contents (Fig. $2 B$ ).

Then we directly determined CatS enzymatic activity in the
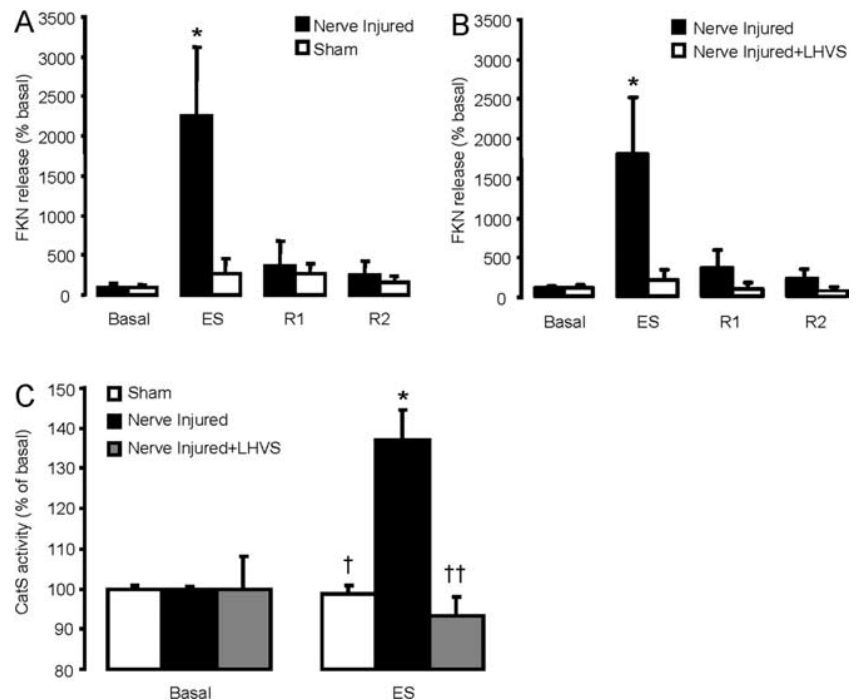

Figure 2. $E S$ of $L 4$ and $L 5$ dorsal roots evokes release of FKN in a CatS-dependent manner from the dorsal horn $7 \mathrm{~d}$ after partial ligation of the sciatic nerve. $A$, In nerve-injured dorsal horn slices, but not sham slices, ES (75 trains of four pulses separated by $0.2 \mathrm{~ms}, 100 \mathrm{~Hz} ; 20 \mathrm{~V}$ intensity, 0.5 ms duration) of ipsilateral $L 4$ and $L 5$ dorsal roots evokes significant release of FKN over basal. Basal release: Nerve injured $=0.3 \pm 0.1 \mathrm{pg} / 3 \mathrm{ml}$ fraction $(n=7$ slices), sham $=$ $0.7 \pm 0.1 \mathrm{pg} / 3 \mathrm{ml}$ fraction ( $n=8$ slices). FKN levels returned to basal in $3 \mathrm{ml}$ recovery fractions $\mathrm{R} 1$ and R2. $\boldsymbol{B}$, In nerve-injured dorsal horns, the presence of LHVS ( $1 \mu \mathrm{m}$; before and during stimulation) inhibits electrically evoked FKN release compared with ES alone. Basal release: Nerve injured $=0.5 \pm 0.1 \mathrm{pg} / 3 \mathrm{ml}$ fraction $(n=9$ slices), nerve injured + LHVS $=0.5 \pm 0.2$ $\mathrm{pg} / 3 \mathrm{ml}$ fraction ( $n=9$ slices). ${ }^{*} p<0.05$ compared with basal levels, one-way ANOVA, post hoc Tukey's test. C, In nerve-injured dorsal horn slices, but not sham slices, ES evokes a significant increase in CatS enzymatic activity in superfusates compared with basal. Data represent mean \pm SEM of representative experiment measuring CatS enzymatic activity in fluorescence units per $10 \mathrm{~min}$ incubation. Experiment replicated four times per treatment. ${ }^{*} p<0.05 \mathrm{com}$ pared with basal levels, ${ }^{\dagger} p<0.05,{ }^{+\dagger} p<0.01$ compared with nerve-injured ES group, oneway ANOVA, post hoc Tukey's test.

dorsal horn superfusates. In sham samples, CatS activity was detected under basal conditions and did not change after stimulation of the dorsal roots (Fig. 2C). In contrast, in nerve-injured samples, electrical stimulation induced an increase in CatS activity of $35 \%$ over prestimulation activity (Fig. $2 C$ ), which was completely prevented by the presence of LHVS (Fig. 2C). These data provide indirect and direct evidence that active Cat $S$ is secreted in the dorsal horn under the conditions in which sFKN liberation occurs.

Consistent with the idea that $\mathrm{sFKN}$ liberation requires CatS release from activated microglia, we observed that the intensity of intracellular CatS-ir in nerve-injured dorsal horn slices was decreased after electrical stimulation (Fig. $3 B, D$ ) of the dorsal roots compared with nonstimulated nerve-injured slices (Fig. $3 C, D$ ), which showed higher CatS-ir intensity than sham or naive slices (Fig. $3 A, D$ ) in microglial cells. LHVS prevented electrical stimulation-evoked decrease in intracellular CatS-ir in slices obtained from nerve-injured rats (Fig. 3D). In addition, we observed that the number of cells expressing CatS, as well as the microglial cell markers Iba- 1 and p-p38 MAPK, was increased in nerve-injured compared with sham slices (Fig. $3 E-K$ ), thereby confirming that dorsal horn microglia become activated as a result of peripheral nerve damage.

Microglial cell numbers (CatS, Iba-1, p-p38 positive) remained unaffected by stimulation of primary afferents, either in the presence or absence of LHVS (Fig. 3E-K), suggesting that nerve injury-induced microglial activation observed in dorsal 

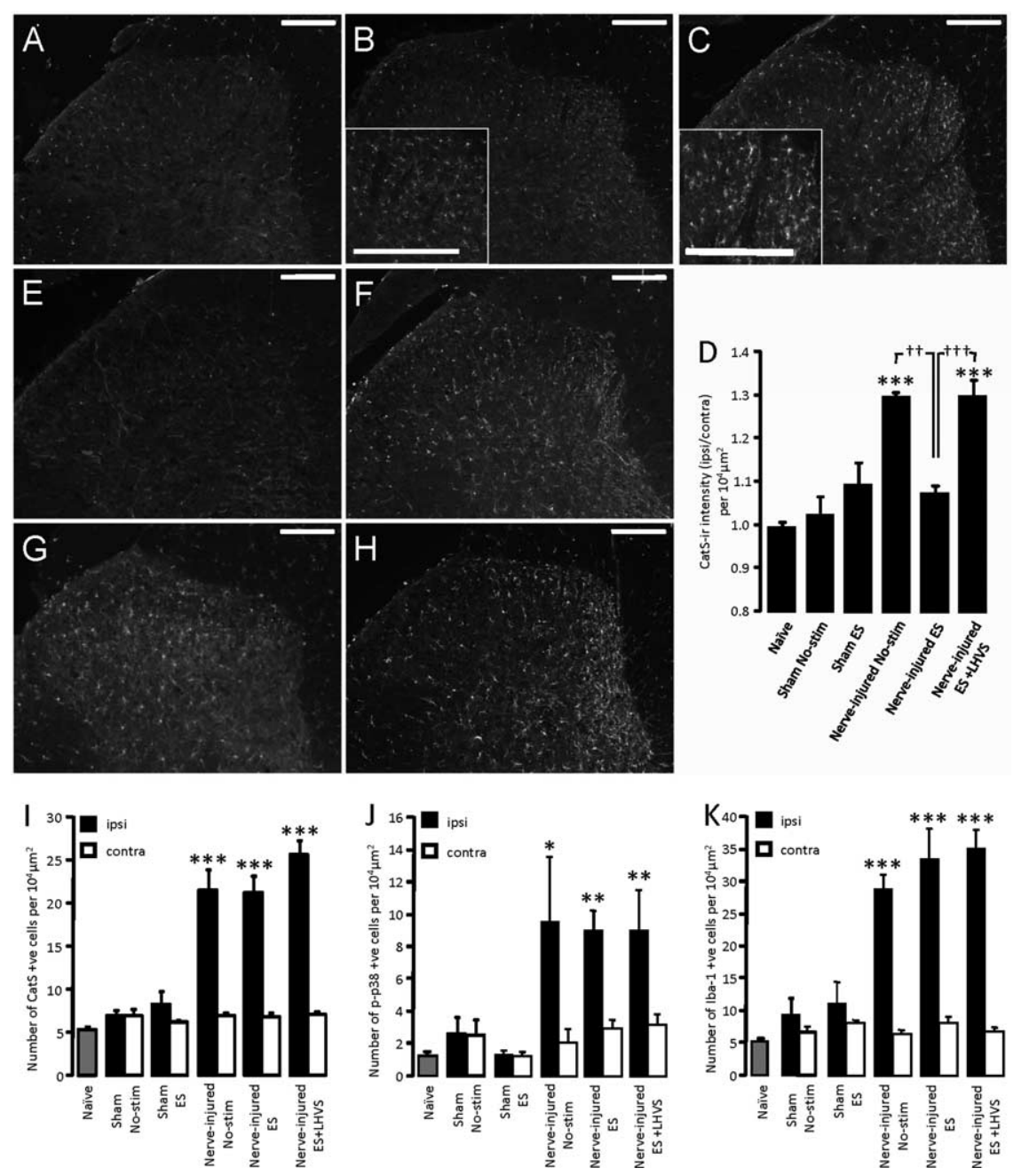

Figure 3. ES of the dorsal roots reduces intracellular CatS-ir, but microglial cell numbers in the dorsal horn remain unchanged. $\boldsymbol{A}-\boldsymbol{C}$, CatS-ir in sham $(\boldsymbol{A})$ and nerve injured $(\boldsymbol{B})$ dorsal horn slices after $E S$, and in unstimulated nerve-injured slices ( $\boldsymbol{C}$. High-power images shown as insets in $\boldsymbol{B}$ and $\boldsymbol{C}$. Scale bars, $100 \mu \mathrm{m}$. D, Quantification of CatS-ir intensity in dorsal horn slices. $\boldsymbol{E}, \boldsymbol{F}, \mathrm{p}-\mathrm{p} 38$ MAPK-ir in sham $(\boldsymbol{E})$ and nerve-injured $(\boldsymbol{F})$ dorsal horn slices after ES. $\boldsymbol{G}, \boldsymbol{H}$, Iba-1-ir in sham $(\boldsymbol{G})$ and nerve-injured $(\boldsymbol{H})$ dorsal horn slices after ES. I-K, Quantification of CatS $(\boldsymbol{I})$-, p-p38 (J)-, and Iba-1 $(\boldsymbol{K})$-positive microglia cells in dorsal horn slices. ${ }^{*} p<0.05$, ${ }^{* *} p<0.01$, ${ }^{* * *} p<0.001$ compared with naive; ${ }^{{ }^{+\dagger}} p<0.01,{ }^{\dagger+\dagger} p<0.001$ compared with indicated treatment group, one-way ANOVA, post hoc Tukey's test, $n=4-8$ per group.

horn slices cannot be further increased by electrical stimulation of the dorsal roots.

Together these data suggest that it is the combination of noxious-like stimulation of primary afferent fibers and nerve injury-induced activation of microglia that results in secretion of CatS, leading to liberation of sFKN in the dorsal horn. Indeed, noxious-like stimulation of primary afferent fibers alone is insufficient to activate microglial markers or liberate sFKN and CatS in the dorsal horn, and activation of microglia in nerve-injured dorsal horn is not associated with a measurable increase in sFKN and CatS activity, as basal levels of both the chemokine and the protease were comparable to sham slice levels.

\section{LPS evokes slow release of FKN in the dorsal horn}

To provide further evidence supporting the idea that activation of microglia is essential for liberation of sFKN from neurons in the dorsal horn, we acutely activated spinal microglia using LPS (Clark et al., 2006) in the absence of nerve injury. LPS activates Toll-like receptor 4 (TLR4), which is exclusively expressed by microglial cells in the dorsal horn and has been suggested to contribute to neuropathic pain, as TLR4 null mice develop less severe allodynia than wild-type mice after peripheral nerve injury (Tanga et al., 2005). Superfusion of LPS through the dorsal horn is sufficient to induce release of IL- $1 \beta$ and caspase- 1 (Clark et al., 2006), most likely because the levels of ATP are high enough to promote $\mathrm{P} 2 \mathrm{X} 7$ activation on microglia (Clark et al., 2006, 2008).

Here, superfusion of LPS through the isolated dorsal horn resulted in a significant, but delayed, increase of FKN content in dorsal horn superfusates (Fig. $4 A$, black bars). A trend for increases in FKN levels was observed during the 8 min LPS superfusion and the first $8 \mathrm{~min}$ recovery fraction (R1); however, FKN changes reached significant levels in the second 8 min recovery fraction (R2, 16-24 min after LPS application commenced). In these three fractions, total LPS-induced FKN liberation reached $3000 \%$ of basal values.

In addition, LPS superfusion induced a significant increase in secreted CatS enzymatic activity in superfusates compared with basal levels (Fig. 4A, gray diamonds). This secretion of CatS peaked in the fraction during LPS superfusion, suggesting direct release of CatS from spinal microglia before the observed peak in sFKN liberation. The delayed LPS-induced release of FKN indicates that LPS-induced FKN liberation is not likely to occur from the activated microglia themselves, but rather, via indirect mechanism(s) which nevertheless require(s) microglial activation. In contrast, LPS-induced release of IL- $1 \beta$ occurred in the fraction collected during LPS application (Fig. 4C), consistent with direct IL- $1 \beta$ release from microglial cells (Clark et al., 2006).

We then observed that superfusion of LHVS, before and during LPS stimulation, completely inhibited LPS-evoked release of sFKN (Fig. $4 B$ ), suggesting that active CatS is critical for liberation of this chemokine in dorsal horn superfusates. Furthermore, LHVS significantly reduced LPS-induced release of IL- $1 \beta$ in the dorsal horn (Fig. $4 C$ ) and reduced LPSinduced phosphorylation of $\mathrm{p} 38 \mathrm{MAPK}$ in microglia (Fig. $4 D, E$ ), indicating that inhibition of CatS in spinal microglia results in reduction of microglial function, including the release of cytokines. Finally, the observation that intrathecal LPS-induced mechanical hyperalgesia (Clark et al., 2006) was completely abolished by concomitant administration of LHVS (Fig. $4 F$ ) underscores the relevant role played by CatS-mediated pathways in the behavioral effects associated with intrathecal injection of LPS.

\section{Dorsal horn neurons are the source for FKN liberation}

When examining the intensity of FKN-ir in dorsal horn slices, we found that this remained unaltered in naive, sham, and nerveinjured slices even after electrical stimulation of primary afferent fibers (FKN-ir ipsi/contra: naive, $1.03 \pm 0.06$; sham, $1.01 \pm 0.03$; nerve injured, $1.02 \pm 0.07$ ), suggesting that the abundance of 
spinal FKN expression limits the detection of changes of cell-associated chemokine contents even when sFKN is cleaved from neuronal membranes. Indeed, we calculated that the amount of $s F K N$ found in nerve-injured dorsal horn superfusates represented $0.006 \%$ of the chemokine total tissue content, which was $7 \pm 0.9 \mathrm{ng} / 50$ mg slice $(n=10)$. Similarly, whereas cellassociated FKN-ir and FKN tissue contents in nerve-injured dorsal horns remained unchanged from both naive and sham values (Fig. $5 A-C, \mathrm{~F}$ ), sFKN content in CSF samples of nerve-injured rats was significantly higher than that in naive or sham CSF (Fig. 5E). Alongside sFKN, CatS activity in nerve-injured CSF was $331.6 \pm$ $64.8 \%(n=8)$ higher than in control CSF samples (corresponding to 61,225 \pm 8988 fluorescence units; $n=4, p<0.05$ ). These data suggest that although the abundance of spinal FKN masks any reduction in overall FKN content, increases in sFKN, which is the pronociceptive form of this chemokine, can be detected in the CSF of nerveinjured animals. As the CSF pool of sFKN and CatS includes chemokine/protease that has diffused away from the extracellular compartment, these data suggest that central sFKN and CatS increase after nerve injury, and these changes can be measured in the absence of noxious stimulation.

Interestingly, even after dorsal root rhizotomy, the level of FKN-ir in the dorsal horn remained unchanged from naive levels (Fig. 5A,D), suggesting that this chemokine is unlikely to be axonally expressed. In fact, we found that FKN-ir in the naive dorsal horn did not colocalize with either CGRP (Fig. $6 A-D$ ) or IB4 (Fig. $6 E-H)$, providing no evidence for FKN expression by the central terminals of either peptidergic or nonpeptidergic C-fibers. In addition, FKN was not found to colocalize with NF200, a marker of myelinated fibers (Fig. 6I-L). Consistent with previous reports (Verge et al., 2004; Lindia et al., 2005), we observed that FKN-ir in the dorsal horn is colocalized with $\mathrm{NeuN}$, a marker of spinal neurons (Fig. 7A-F). In addition, we examined the localization of FKN mRNA in the dorsal horn. Spinal cord sections were hybridized with FKN biotin-end-labeled oligonucleotide probe followed by immunohistochemistry with NeuN. FKN mRNA was found to colocalize with NeuN-ir (Fig. 7G-I), whereas RNase A-treated sections showed absence of FKN mRNA labeling in NeuN-positive cells (Fig. 7J-L).

These data suggest that FKN is expressed by intrinsic neurons in the dorsal horn, but not by the central terminals of primary afferent fibers terminating in the dorsal horn, and therefore, the likely source of sFKN liberation appears to be spinal neurons.
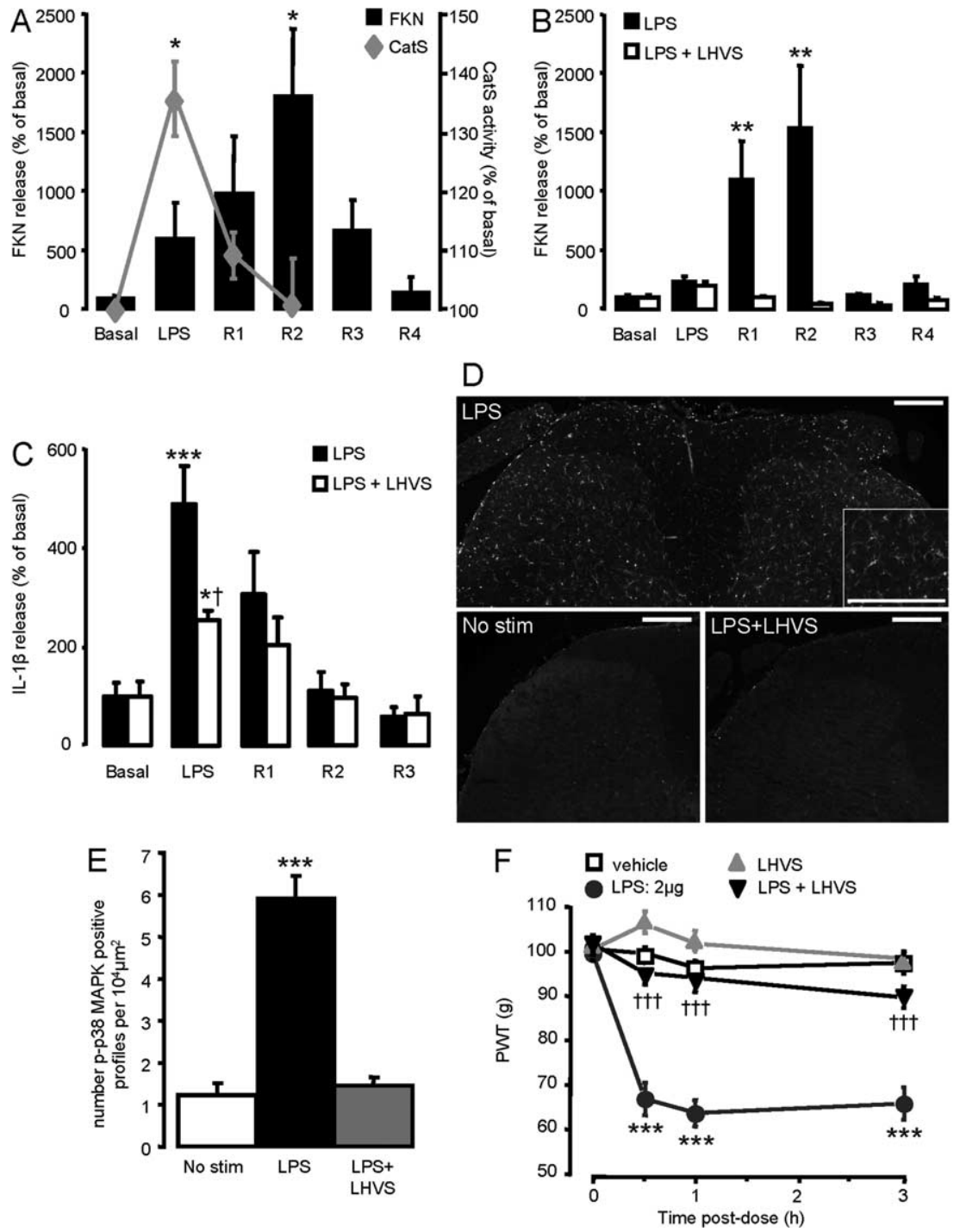

Figure 4. LPS induces a delayed release of FKN from the dorsal horn which is dependent on CatS activity. $A, \operatorname{LPS}(10 \mu \mathrm{g} / \mathrm{ml}$ for $8 \mathrm{~min}$ ) induces an increase in FKN levels (black bars) in dorsal horn superfusates which peaks in the second recovery fraction (R2; collected 24-30 min after LPS application begins; $n=9$ slices). Basal release $=1.0 \pm 0.1 \mathrm{pg} / 8 \mathrm{ml}$ fraction. ${ }^{*} p<0.05$ compared with basal value, one-way ANOVA, post hoc Tukey's test. LPS also induces a significant increase in CatS enzymatic activity (gray diamonds) in superfusates compared with basal, which occurs before FKN liberation. Data represent mean \pm SEM of representative experiment measuring CatS enzymatic activity in fluorescence units per 10 min incubation. Experiment replicated four times per treatment. ${ }^{*} p<0.05$ compared with basal value, one-way ANOVA, post hoc Tukey's test. $\boldsymbol{B}$, LHVS (1 $\left.\mu \mathrm{m}\right)$ incubated before and during LPS superfusion ( $16 \mathrm{~min}$ in total) inhibits LPS-evoked FKN release ( $n=9$ slices) compared with LPS alone ( $n=$ 10 slices). Basal release: $L P S=1.1 \pm 0.1 \mathrm{pg} / 8 \mathrm{ml}$ fraction, $L P S+L H V S=1.0 \pm 0.1 \mathrm{pg} / 8 \mathrm{ml}$ fraction. C, Superfusion of LHVS significantly attenuates LPS-evoked IL- $1 \beta$ release ( $n=6$ slices) compared with LPS alone $(n=7$ slices). LPS $(10 \mu \mathrm{g} / \mathrm{ml}$ for $8 \mathrm{~min})$ induces rapid release of IL-1 $\beta$ in dorsal horn superfusates and the presence of LHVS $(1 \mu \mathrm{M})$ incubated before and during LPS superfusion (16 min in total) prevents IL-1 $\beta$ release. Basal release: LPS $=8.5 \pm 2.4 \mathrm{pg} / 8 \mathrm{ml}$ fraction, $\mathrm{LPS}+\mathrm{LHVS}=7.3 \pm 2.2$ $\mathrm{pg} / 8 \mathrm{ml}$ fraction. ${ }^{*} p<0.05,{ }^{* *} p<0.01,{ }^{* * *} p<0.001$ compared with basal value, ${ }^{\dagger} p<0.05$ compared with LPS group, one-way ANOVA, post hoc Tukey's test. D, LHVS $(1 \mu \mathrm{m})$ superfusion before and during LPS superfusion inhibits LPS-evoked p38 MAPK phosphorylation in the dorsal horn. High-power image after LPS superfusion alone shown as inset. Scale bars, $100 \mu \mathrm{m}$. E, Quantification of p-p38 immunoreactivity ( $n=6$ slices per group). ${ }^{* * *} p<0.001$, one-way ANOVA, post hoc Tukey's test. $F$, Intrathecal LPS (two times, $2 \mu \mathrm{g} / 10 \mu \mathrm{l} /$ rat) produces significant mechanical hyperalgesia which is prevented by concomitant administration of LHVS $(50 \mathrm{nmol} / 10$ $\mu \mathrm{l} /$ rat) $\left(n=6\right.$ per group). Each data point represents the mean \pm SEM of PWT in grams. ${ }^{* * *} p<0.001$ compared with vehicle-treated group, ${ }^{+t+} p<0.001$ compared with LPS-treated group, two-way ANOVA, post hoc Tukey's test.

\section{Discussion}

We show that $\mathrm{sFKN}$ is liberated in the dorsal horn of the spinal cord after noxious-like stimulation of injured primary afferent fibers, although exclusively in the presence of activated microglia. Indeed, activation of microglia results in liberation of sFKN in the dorsal horn regardless of concomitant activation of primary af- 

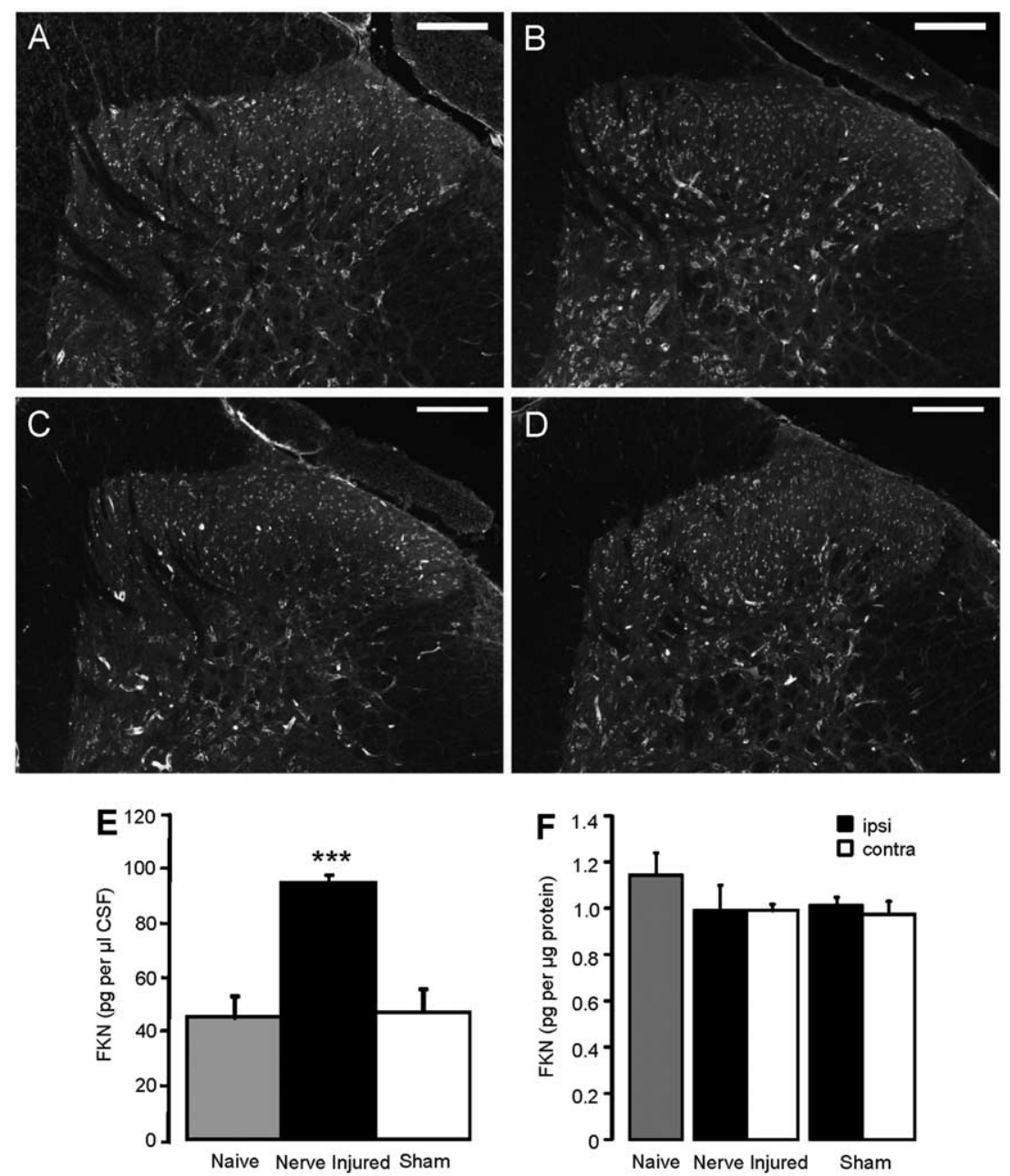

Figure 5. Soluble FKN in the CSF is increased after peripheral nerve injury, whereas cell-associated FKN is not altered. $\boldsymbol{A}-\boldsymbol{D}$, FKN-ir in the naive $(\boldsymbol{A})$ dorsal horn of the spinal cord and $7 \mathrm{~d}$ after peripheral nerve injury $(\boldsymbol{B})$, sham surgery $(\boldsymbol{C})$, and rhizotomy $(\boldsymbol{D})$. Scale bars, $100 \mu \mathrm{m}$. $\boldsymbol{E}$, FKN levels in the CSF of nerve-injured animals is increased compared with naive and sham animals $(n=$ 4-6 per group). ${ }^{* *} p<0.001$, one-way ANOVA, post hoc Tukey's test. $\boldsymbol{F}$, Nerve injury does not alter total FKN levels in the dorsal horn of the spinal cord ( $n=4-6$ per group).

ferent fibers. We argue that it is the release of the protease CatS from activated microglia that mediates cleavage of sFKN from neuronal membranes. We suggest that after nerve injury, primary afferent fiber activity and release of mediators such as ATP promote release of CatS from activated microglial cells, resulting in fast liberation of sFKN, which occurs within a matter of a few minutes. Conversely, the activation of spinal resting microglia by LPS produces liberation of sFKN within a time frame of 20-30 min, which is in line with the observation that increases in CatS activity are observed as early as $8 \mathrm{~min}$ after application of LPS to the dorsal horn, and LPS stimulation of microglial cell lines results in secretion of CatS activity beginning as early as $15 \mathrm{~min}$ after application (Liuzzo et al., 1999).

Detection of higher sFKN levels and CatS activity in the CSF of peripherally nerve-injured, compared with noninjured, rats suggests that FKN and CatS are continuously liberated in the spinal cord under conditions associated with spinal microglial activation and neuropathic pain in the absence of neuronal death (Polgár et al., 2005). Thus, the enhanced expression of microglial CX3CR1 after nerve injury (Verge et al., 2004; Lindia et al., 2005), associated with the increase in CX3CR1 activation induced by enhanced sFKN levels, would facilitate nociception, and as a con- sequence, both CX3CR1 receptor antagonists, similar to CatS inhibitors (Clark et al., 2007; Irie et al., 2008), should result in pain relief. The activation of spinal microglia resulting from peripheral tissue injury can be viewed as an adaptive response to tissue stress or para-inflammation (Medzhitov, 2008). In this context, the microglial mechanisms, including enhanced FKN/CX3CR1 signaling, contributing to chronic pain would constitute nonadaptive processes that may be detrimental and should be prevented. In contrast, in neurodegenerative diseases, the neuronal FKN/microglial CX3CR1 system plays a neuroprotective role aiming to restore tissue functionality, which should therefore be preserved (Cardona et al., 2006).

We have previously suggested that the pronociceptive effects of the cysteine protease CatS are mediated by FKN (Clark et al., 2007). Here we provide evidence demonstrating the role of CatS in FKN liberation in the spinal cord after peripheral nerve injury. First, after nerve injury, CatS enzymatic activity is enhanced in dorsal horn superfusates and CSF under the conditions in which sFKN liberation is observed. Indeed, CatS activity is also secreted after acute microglial activation by LPS, before the detected changes in sFKN. Second, the irreversible, lysosomotropic CatS inhibitor LHVS effectively inhibits CatS activity as well as the liberation of FKN in the dorsal horn. In addition, intracellular CatS-ir is reduced in nerve-injured dorsal horn slices after electrical stimulation of primary afferent fibers. Interestingly, the presence of the lysosomotropic LHVS prevented this reduction in CatS expression, suggesting that LHVS may inhibit the release of CatS from intracellular pools alongside inhibiting extracellular enzymatic activity. It is possible that because of the autocatalytic nature of CatS (Turk et al., 2000, 2001) the inhibition of enzyme activity by LHVS, and therefore its turnover, results in accumulation of the inactive enzyme.

Our data suggest that in the dorsal horn, the source of FKN is likely to be intrinsic neurons as both FKN mRNA and protein are restricted to intrinsic dorsal horn neurons. We and others have provided evidence that FKN is expressed by the cell bodies of sensory neurons in the DRG (Verge et al., 2004; Lindia et al., 2005; Clark et al., 2007). However, it is possible that either the chemokine is not transported to the central terminals of the sensory neurons in the dorsal horn as cell-associated FKN staining and total tissue content remains unaltered after either peripheral nerve injury or dorsal root rhizotomy, or that the abundance of spinal FKN limits the detection of axonal FKN using immunohistochemistry.

These findings suggest that under neuropathic conditions, the increased nociceptive primary afferent inputs to the dorsal horn determine release of microglial CatS, which liberates FKN from dorsal horn neurons, thereby contributing to the amplification and maintenance of chronic pain via activation of CX3CR1 receptors on 

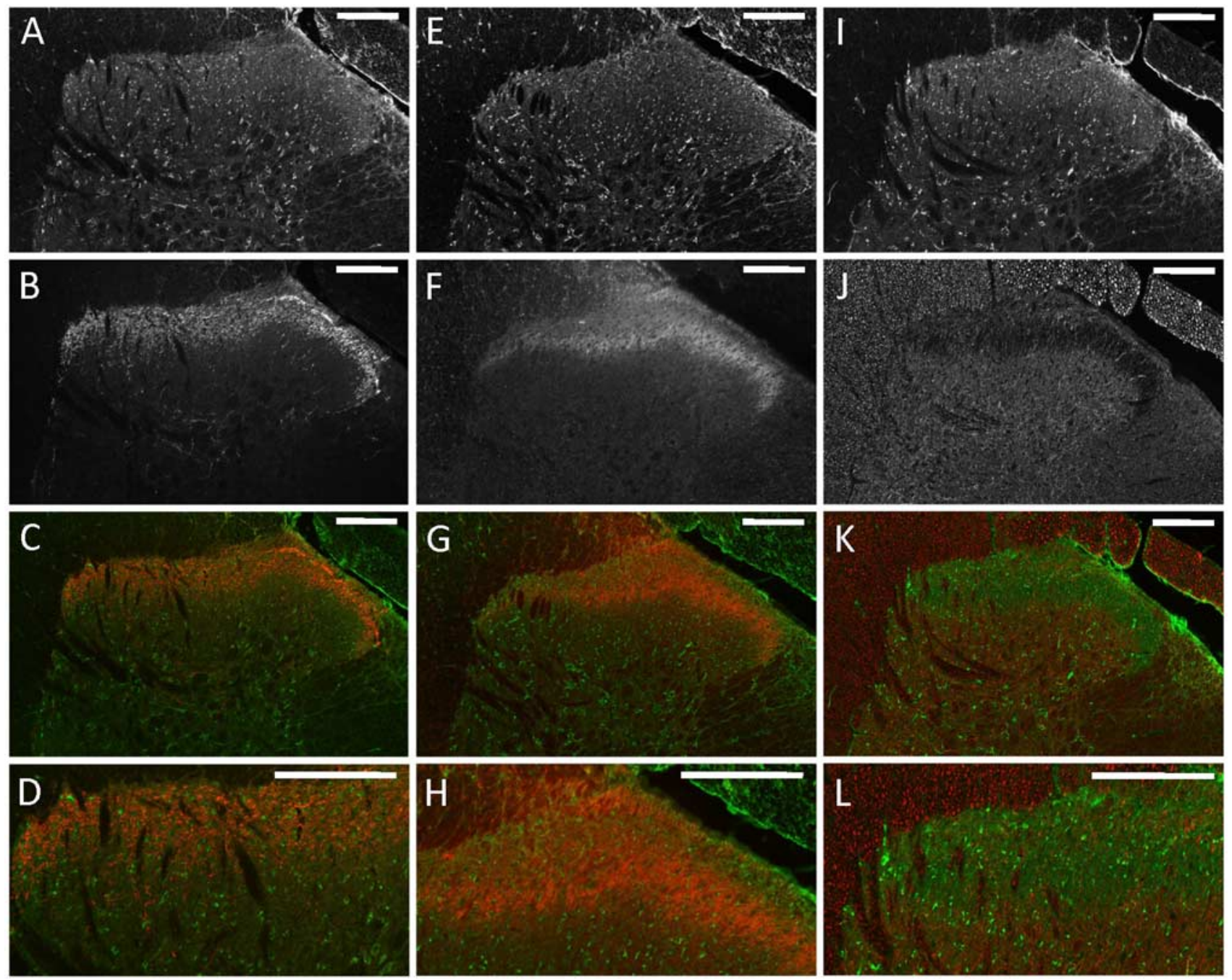

Figure 6. FKN is not expressed by primary afferent terminals in the dorsal horn of the spinal cord. FKN-ir $(\boldsymbol{A}, \boldsymbol{E}, \boldsymbol{I})$ in the dorsal horn does not colocalize with $C G R P(B ; C, D=$ merge), IB4 $(\boldsymbol{F} ; \boldsymbol{G}, \boldsymbol{H}=$ merge) or NF200 ( $\boldsymbol{J} \boldsymbol{K}, \boldsymbol{L}=$ merge). $\boldsymbol{D}, \boldsymbol{H}$, and $\boldsymbol{L}$ represent higher magnification of merged images in $\boldsymbol{C}, \boldsymbol{G}$, and $\boldsymbol{K}$, respectively. Scale bars, $100 \mu \mathrm{m}$.

microglia. This possibility is corroborated by the notion that CatS is upregulated in the dorsal horn during the maintenance phase of neuropathic pain and the idea that the microglial CatS/neuronal FKN pair establishes a positive feedback which contributes to chronic pain state persistence (Clark et al., 2007).

Activation of microglia in the spinal cord has been identified in many models of neuropathic pain (Scholz and Woolf, 2007; Romero-Sandoval et al., 2008; Milligan and Watkins, 2009), and enhanced excitatory drive from primary sensory neurons into the dorsal horn results in the sequential activation of microglia then astrocytes. These activated glial cells then help initiate and maintain enhanced pain signaling by releasing pronociceptive mediators (Scholz and Woolf, 2007; Romero-Sandoval et al., 2008; Abbadie et al., 2009; Milligan and Watkins, 2009). The signals responsible for neuronal-microglial-astrocytic communication are being actively investigated as they may reveal new mechanisms and targets for chronic pain. The observations that local anesthetic block of primary afferent input blocks hyperalgesia and glial activation (Guo et al., 2007; Wen et al., 2007) indicate that this activation depends on neuronal input and neurotransmitter release. However, primary afferent input is not required for the maintenance of microglial activation (Wen et al., 2007), as we show here for sFKN liberation. The obvious neuronal candi- dates such as glutamate and substance $\mathrm{P}$, which are released after activation of nociceptive primary afferent fibers in the dorsal horn (Lever et al., 2001), have been shown to activate microglial cells (Svensson et al., 2003a,b). The effects of glutamate and substance $\mathrm{P}$ are directly mediated by activation of NMDA receptors (Svensson et al., 2003a) and NK1 receptors on microglia (Rasley et al., 2002), respectively. However, it is unlikely that either glutamate or substance P is essential for FKN cleavage since their release from primary afferent terminals occurs under naive conditions (Lever et al., 2001), which are not associated with either microglial activation or sFKN liberation.

Another likely mediator of neuronal-microglial communication is ATP, which can be produced by neurons as well as glial cells, and can activate microglial P2X4 and P2X7 receptors as well as metabotropic receptors such as P2Y6 and P2Y12 (Inoue et al., 2007). After peripheral nerve injury, the $\mathrm{P} 2 \mathrm{X} 4$ receptor is upregulated in dorsal horn microglia (Tsuda et al., 2003; Ulmann et al., 2008) where it contributes to the development of neuropathic allodynia by inducing the release of BDNF (Coull et al., 2005; Ulmann et al., 2008; Trang et al., 2009). The maintenance of microglial activation is likely to be performed by P2X7 receptors, which require high concentrations of extracellular ATP as associated with tissue stress. In P2X7 knock-out mice the develop- 

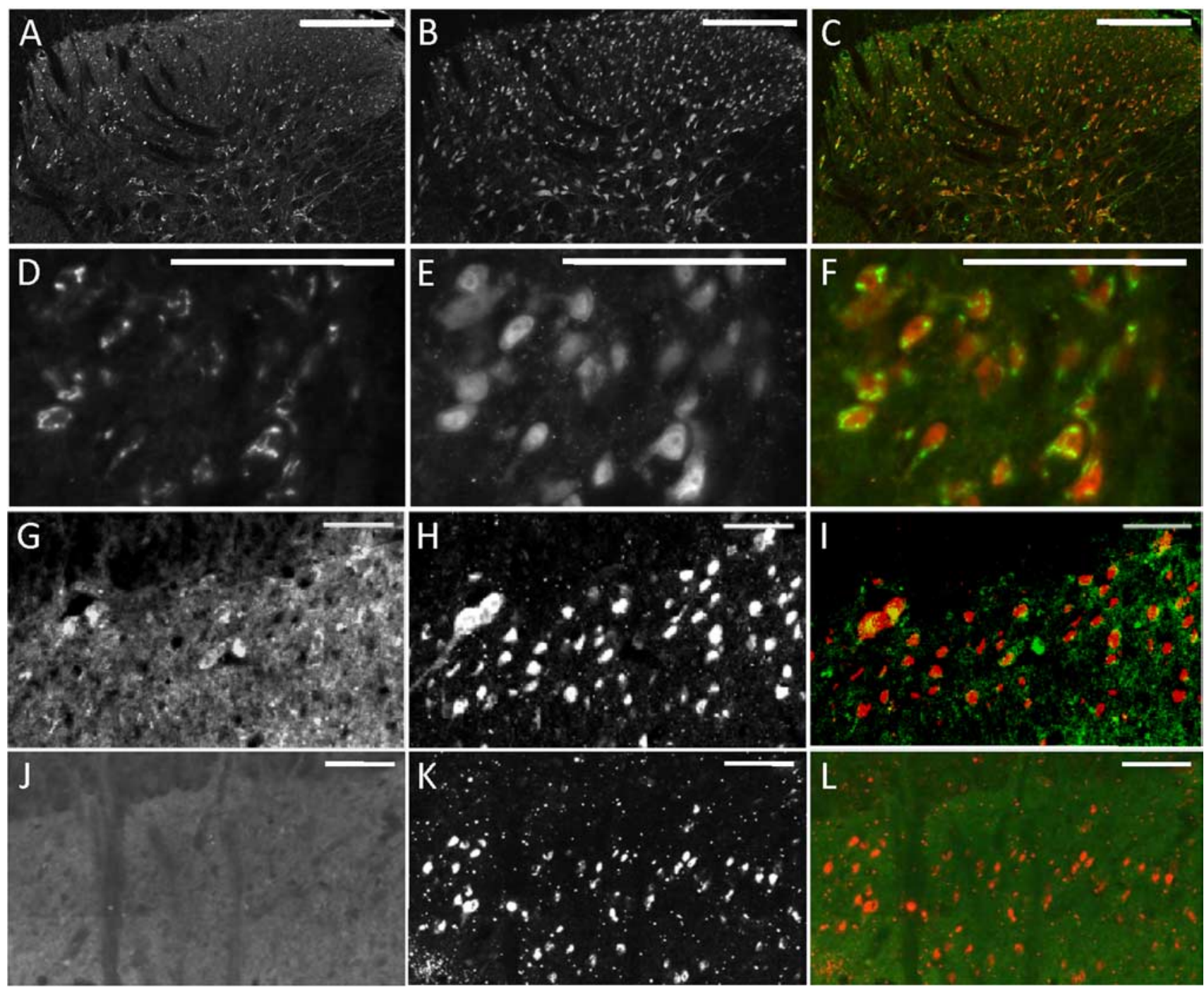

Figure 7. FKN protein and mRNA are expressed by spinal dorsal horn neurons. $\boldsymbol{A}-\boldsymbol{F}, \mathrm{FKN}-\mathrm{ir}(\boldsymbol{A}, \boldsymbol{D})$ in the dorsal horn of the spinal cord colocalizes with the neuronal marker NeuN $(\boldsymbol{B}, \boldsymbol{E} ; \boldsymbol{C}, \boldsymbol{F}=$ merge). Scale bars, $100 \mu \mathrm{m}$. G-L, In situ localization of FKN mRNA in the dorsal horn. Spinal cord sections were hybridized with FKN biotin-end-labeled oligonucleotide probe followed by immunohistochemistry for NeuN. FKN mRNA (G) colocalized with NeuN-ir ( $\boldsymbol{H} ; \boldsymbol{I}=$ merge). RNase A-treated sections showed absence of FKN mRNA $(\boldsymbol{J})$ labeling in NeuN-positive cells $(\boldsymbol{K} ; \boldsymbol{L}=$ merge). Scale bars, $50 \mu \mathrm{m}$.

ment of both thermal and mechanical hyperalgesia is prevented in models of neuropathic and inflammatory pain (Chessell et al., 2005), and P2X7 antagonists are effective at attenuating neuropathic pain (McGaraughty et al., 2007), possibly via decreased maturation and release of IL-1 $\beta$ (Chessell et al., 2005; McGaraughty et al., 2007; Clark et al., 2008).

A unique role as communicator between neurons and microglia is played by the chemokine CCL2, which is de novo expressed by sensory neurons as soon as $1 \mathrm{~d}$ after injury (Tanaka et al., 2004; Thacker et al., 2009). After nerve injury, CCL2 is released with activity by a subset of primary afferent fibers in the dorsal horn of the spinal cord (Thacker et al., 2009) and activates microglia via interaction with CCR2 receptors. Signaling from CCL2 to its receptor CCR2 is critical in spinal microglial activation (Thacker et al., 2009), and CCR2 null mice develop less severe allodynia than do wild types (Abbadie et al., 2003). Thus, CCL2 may be playing a key role in microglial activation and subsequent FKN liberation, due to its activity-dependent release from primary afferent terminals in the dorsal horn after nerve injury (Thacker et al., 2009).

In conclusion, we suggest that in the neuropathic pain scenario, increased afferent drive in the dorsal horn of the spinal cord, which is associated with the release of primary afferent fiber transmitters such as ATP and substance P, as well as de novo transmitters such as CCL2, determines the early activation of microglial cells in the initiation of chronic pain mechanisms. Instead, sFKN and CatS play an essential role in the amplification and maintenance of mechanisms mediated by microglial pathways, which may represent nonadaptive processes leading to neuropathic pain.

\section{References}

Abbadie C, Lindia JA, Cumiskey AM, Peterson LB, Mudgett JS, Bayne EK, DeMartino JA, MacIntyre DE, Forrest MJ (2003) Impaired neuropathic pain responses in mice lacking the chemokine receptor CCR2. Proc Natl Acad Sci U S A 100:7947-7952.

Abbadie C, Bhangoo S, De Koninck Y, Malcangio M, Melik-Parsadaniantz S, White FA (2009) Chemokines and pain mechanisms. Brain Res Rev 60:125-134.

Barclay J, Clark AK, Ganju P, Gentry C, Patel S, Wotherspoon G, Buxton F, Song C, Ullah J, Winter J, Fox A, Bevan S, Malcangio M (2007) Role of the cysteine protease cathepsin $S$ in neuropathic hyperalgesia. Pain 130:225-234.

Bazan JF, Bacon KB, Hardiman G, Wang W, Soo K, Rossi D, Greaves DR, Zlotnik A, Schall TJ (1997) A new class of membrane-bound chemokine with a CX3C motif. Nature 385:640-644. 
Cahill CM, Dray A, Coderre TJ (2003) Enhanced thermal antinociceptive potency and anti allodynic effects of morphine following spinal administration of endotoxin. Brain Res 960:209-218.

Cardona AE, Pioro EP, Sasse ME, Kostenko V, Cardona SM, Dijkstra IM, Huang D, Kidd G, Dombrowski S, Dutta R, Lee JC, Cook DN, Jung S, Lira SA, Littman DR, Ransohoff RM (2006) Control of microglial neurotoxicity by the fractalkine receptor. Nat Neurosci 9:917-924.

Chessell IP, Hatcher JP, Bountra C, Michel AD, Hughes JP, Green P, Egerton J, Murfin M, Richardson J, Peck WL, Grahames CB, Casula MA, Yiangou Y, Birch R, Anand P, Buell GN (2005) Disruption of the P2X7 purinoceptor gene abolishes chronic inflammatory and neuropathic pain. Pain 114:386-396.

Clark AK, D'Aquisto F, Gentry C, Marchand F, McMahon SB, Malcangio M (2006) Rapid co-release of interleukin lbeta and caspase 1 in spinal cord inflammation. J Neurochem 99:868-880.

Clark AK, Yip PK, Grist J, Gentry C, Staniland AA, Marchand F, Dehvari M, Wotherspoon G, Winter J, Ullah J, Bevan S, Malcangio M (2007) Inhibition of spinal microglial cathepsin $\mathrm{S}$ for the reversal of neuropathic pain. Proc Natl Acad Sci U S A 104:10655-10660.

Clark AK, Marchand F, Blanchet A-S, McMahon SB, Malcangio M (2008) $\mathrm{P} 2 \mathrm{X} 7$ dependent release of interleukin $1 \beta$ and nociception in spinal cord inflammation. International Association for the Study of Pain, 12th World Congress on Pain (abstr) PH 351.

Coull JA, Beggs S, Boudreau D, Boivin D, Tsuda M, Inoue K, Gravel C, Salter MW, De Koninck Y (2005) BDNF from microglia causes the shift in neuronal anion gradient underlying neuropathic pain. Nature 438:1017-1021.

Guo W, Wang H, Watanabe M, Shimizu K, Zou S, LaGraize SC, Wei F, Dubner R, Ren K (2007) Glial-cytokine-neuronal interactions underlying the mechanisms of persistent pain. J Neurosci 27:6006-6018.

Inoue K, Tsuda M, Tozaki-Saitoh H (2007) Modification of neuropathic pain sensation through microglial ATP receptors. Purinergic Signal 3:311-316.

Irie O, Kosaka T, Ehara T, Yokokawa F, Kanazawa T, Hirao H, Iwasaki A, Sakaki J, Teno N, Hitomi Y, Iwasaki G, Fukaya H, Nonomura K, Tanabe K, Koizumi S, Uchiyama N, Bevan SJ, Malcangio M, Gentry C, Fox AJ, et al. (2008) Discovery of orally bioavailable cathepsin S inhibitors for the reversal of neuropathic pain. J Med Chem 51:5502-5505.

Kirschke H, Wiederanders B (1994) Cathepsin S and related lysosomal endopeptidases. Methods Enzymol 244:500-511.

Lever IJ, Bradbury EJ, Cunningham JR, Adelson DW, Jones MG, McMahon SB, Marvizón JC, Malcangio M (2001) Brain-derived neurotrophic factor is released in the dorsal horn by distinctive patterns of afferent fiber stimulation. J Neurosci 21:4469-4477.

Lindia JA, McGowan E, Jochnowitz N, Abbadie C (2005) Induction of CX3CL1 expression in astrocytes and CX3CR1 in microglia in the spinal cord of a rat model of neuropathic pain. J Pain 6:434-438.

Liuzzo JP, Petanceska SS, Moscatelli D, Devi LA (1999) Inflammatory mediators regulate cathepsin $\mathrm{S}$ in macrophages and microglia: a role in attenuating heparan sulfate interactions. Mol Med 5:320-333.

Lützner N, Kalbacher H (2008) Quantifying cathepsin S activity in antigen presenting cells using a novel specific substrate. J Biol Chem 283:36185-36194.

McGaraughty S, Chu KL, Namovic MT, Donnelly-Roberts DL, Harris RR, Zhang XF, Shieh CC, Wismer CT, Zhu CZ, Gauvin DM, Fabiyi AC, Honore P, Gregg RJ, Kort ME, Nelson DW, Carroll WA, Marsh K, Faltynek CR, Jarvis MF (2007) P2X7-related modulation of pathological nociception in rats. Neuroscience 146:1817-1828.

Medzhitov R (2008) Origin and physiological roles of inflammation. Nature 454:428-435.

Milligan E, Zapata V, Schoeniger D, Chacur M, Green P, Poole S, Martin D, Maier SF, Watkins LR (2005) An initial investigation of spinal mechanisms underlying pain enhancement induced by fractalkine, a neuronally released chemokine. Eur J Neurosci 22:2775-2782.

Milligan ED, Watkins LR (2009) Pathological and protective roles of glia in chronic pain. Nat Rev Neurosci 10:23-36.

Milligan ED, Zapata V, Chacur M, Schoeniger D, Biedenkapp J, O'Connor KA, Verge GM, Chapman G, Green P, Foster AC, Naeve GS, Maier SF, Watkins LR (2004) Evidence that exogenous and endogenous fractalkine can induce spinal nociceptive facilitation in rats. Eur J Neurosci 20:2294-2302.

Milligan ED, Sloane EM, Watkins LR (2008) Glia in pathological pain: a role for fractalkine. J Neuroimmunol 198:113-120.

Pan Y, Lloyd C, Zhou H, Dolich S, Deeds J, Gonzalo JA, Vath J, Gosselin M, Ma J, Dussault B, Woolf E, Alperin G, Culpepper J, Gutierrez-Ramos JC,
Gearing D (1997) Neurotactin, a membrane-anchored chemokine upregulated in brain inflammation. Nature 387:611-617.

Polgár E, Hughes DI, Arham AZ, Todd AJ (2005) Loss of neurons from laminas I-III of the spinal dorsal horn is not required for development of tactile allodynia in the spared nerve injury model of neuropathic pain. J Neurosci 25:6658-6666.

Rasley A, Bost KL, Olson JK, Miller SD, Marriott I (2002) Expression of functional NK-1 receptors in murine microglia. Glia 37:258-267.

Rattray M, Michael GJ (1998) In situ hybridisation using oligonucleotide probes. In: In situ hybridisation: a practical approach, Ed 2 (Wilkinson D, ed) pp 23-67. Oxford: Oxford UP.

Romero-Sandoval EA, Horvath RJ, DeLeo JA (2008) Neuroimmune interactions and pain: focus on glial-modulating targets. Curr Opin Investig Drugs 9:726-734.

Scholz J, Woolf CJ (2007) The neuropathic pain triad: neurons, immune cells and glia. Nat Neurosci 10:1361-1368.

Seltzer Z, Dubner R, Shir Y (1990) A novel behavioral model of neuropathic pain disorders produced in rats by partial sciatic nerve injury. Pain 43:205-218.

Svensson CI, Hua XY, Protter AA, Powell HC, Yaksh TL (2003a) Spinal p38 MAP kinase is necessary for NMDA-induced spinal PGE(2) release and thermal hyperalgesia. Neuroreport 14:1153-1157.

Svensson CI, Marsala M, Westerlund A, Calcutt NA, Campana WM, Freshwater JD, Catalano R, Feng Y, Protter AA, Scott B, Yaksh TL (2003b) Activation of p38 mitogen-activated protein kinase in spinal microglia is a critical link in inflammation-induced spinal pain processing. J Neurochem 86:1534-1544.

Tanaka T, Minami M, Nakagawa T, Satoh M (2004) Enhanced production of monocyte chemoattractant protein-1 in the dorsal root ganglia in a rat model of neuropathic pain: possible involvement in the development of neuropathic pain. Neurosci Res 48:463-469.

Tanga FY, Nutile-McMenemy N, DeLeo JA (2005) The CNS role of Tolllike receptor 4 in innate neuroimmunity and painful neuropathy. Proc Natl Acad Sci U S A 102:5856-5861.

Thacker MA, Clark AK, Bishop T, Grist J, Yip PK, Moon LDF, Thompson SWN, Marchand F, McMahon SB (2009) CCL2 is a key mediator of microglia activation in neuropathic pain states. Eur J Pain 13:263-272.

Trang T, Beggs S, Wan X, Salter MW (2009) P2X4-receptor-mediated synthesis and release of brain-derived neurotrophic factor in microglia is dependent on calcium and p38-mitogen-activated protein kinase activation. J Neurosci 29:3518-3528.

Tsuda M, Shigemoto-Mogami Y, Koizumi S, Mizokoshi A, Kohsaka S, Salter MW, Inoue K (2003) P2X4 receptors induced in spinal microglia gate tactile allodynia after nerve injury. Nature 424:778-783.

Turk B, Turk D, Turk V (2000) Lysosomal cysteine proteases: more than scavengers. Biochim Biophys Acta 1477:98-111.

Turk V, Turk B, Turk D (2001) Lysosomal cysteine proteases: facts and opportunities. EMBO J 20:4629-4633.

Ulmann L, Hatcher JP, Hughes JP, Chaumont S, Green PJ, Conquet F, Buell GN, Reeve AJ, Chessell IP, Rassendren F (2008) Up-regulation of P2X4 receptors in spinal microglia after peripheral nerve injury mediates BDNF release and neuropathic pain. J Neurosci 28:11263-11268.

Verge GM, Milligan ED, Maier SF, Watkins LR, Naeve GS, Foster AC (2004) Fractalkine (CX3CL1) and fractalkine receptor (CX3CR1) distribution in spinal cord and dorsal root ganglia under basal and neuropathic pain conditions. Eur J Neurosci 20:1150-1160.

Wen YR, Suter MR, Kawasaki Y, Huang J, Pertin M, Kohno T, Berde CB, Decosterd I, Ji RR (2007) Nerve conduction blockade in the sciatic nerve prevents but does not reverse the activation of p38 mitogen-activated protein kinase in spinal microglia in the rat spared nerve injury model. Anesthesiology 107:312-321.

Wong LF, Yip PK, Battaglia A, Grist J, Corcoran J, Maden M, Azzouz M, Kingsman SM, Kingsman AJ, Mazarakis ND, McMahon SB (2006) Retinoic acid receptor beta2 promotes functional regeneration of sensory axons in the spinal cord. Nat Neurosci 9:243-250.

Zaidi AU, Enomoto H, Milbrandt J, Roth KA (2000) Dual fluorescent in situ hybridization and immunohistochemical detection with tyramide signal amplification. J Histochem Cytochem 48:1369-1375.

Zhuang ZY, Kawasaki Y, Tan PH, Wen YR, Huang J, Ji RR (2007) Role of the CX3CR1/p38 MAPK pathway in spinal microglia for the development of neuropathic pain following nerve injury-induced cleavage of fractalkine. Brain Behav Immun 21:642-651. 